Revue d'histoire de l'Amérique française

DE REVUE D'HISTOIRE DE L'AMÉRIQUE FRANÇAISE

\title{
Étude caractériologique de Mère Marguerite Bourgeoys d'après douze documents autographes de 1651 à 1695
}

Volume 20, numéro 1, juin 1966

URI : https://id.erudit.org/iderudit/302542ar

DOI : https://doi.org/10.7202/302542ar

Aller au sommaire du numéro

Éditeur(s)

Institut d'histoire de l'Amérique française

ISSN

0035-2357 (imprimé)

1492-1383 (numérique)

Découvrir la revue

Citer ce document

(1966). Étude caractériologique de Mère Marguerite Bourgeoys d'après douze documents autographes de 1651 à 1695. Revue d'histoire de l'Amérique

française, 20(1), 75-107. https://doi.org/10.7202/302542ar d'utilisation que vous pouvez consulter en ligne.

https://apropos.erudit.org/fr/usagers/politique-dutilisation/ 


\section{DOCUMENTS INÉDITS}

Étude caractériologique

de

Mère Marguerite Bourgeoys

d'après

douze documents autographes

de

1651 à 1695 


\title{
GENÈSE D'UNE ÉTUDE GRAPHOLOGIQUE
}

\author{
sur \\ MARGUERITE BOURGEOYS
}

$\mathrm{Au}$ cours d'une retraite prêchée à Nicolet, en 1964, un religieux Carme, parlant de saint Jean de la Croix, en présenta le caractère étudié par une experte en graphologie, Suzanne Bressard, de Paris.

Une Sœur de la Congrégation de Notre-Dame eut alors l'inspiration de proposer à la directrice du Centre MargueriteBourgeoys, de faire entreprendre une semblable étude sur la fondatrice de ia Congrégation de Notre-Dame, ia bienheureuse Marguerite Bourgeoys. Elle communiqua aussi à la directrice l'adresse d'un intermédiaire compétent, le révérend Père Élie, du Carmel de Paris.

Une brève correspondance avec ce religieux, qui ne pouvait plus retracer Mlle Bressard, aboutit quand même à un heureux résultat: mise en relations avec la direction de l'International Psycho-Service de Paris, hautement recommandé. Madame A. Roque, directrice de l'Institut, acceptait d'étudier le caractère de Marguerite Bourgeoys d'après une série de documents échelonnés sur une période de quarante-quatre années (1651-1695).

En novembre 1965 le travail était remis au Centre Marguerite-Bourgeoys. Grâce à la bienveillance de M. le chanoine Groulx, ce travail paraît en primeur dans sa Revue et nous lui sommes profondément reconnaissantes qu'il en écrive la présentation.

Les Sceurs de la Congrégation de Notre-Dame

par Sceur SAINT-Damase-DE-ROME (MARIE-ANNE GAUTHIER-LANDREVILLE) 


\section{PRÉSENTATION}

Nous publions, sur Marguerite Bourgeoys, quelques documents d'importance majeure. Cette femme aura été l'un des grands personnages de notre histoire. A la Ville-Marie de son époque historique elle a prêté son assistance. En fondant une sorte d'école ménagère au profit des "Filles du Roy", elle a préparé quelques-unes de nos mères de famille. Elle s'est faite institutrice; elle a été la première à fonder nos écoles de campagne. Elle nous a laissé l'exemple d'une sainte fille de Dieu. C'est plus qu'il ne faut pour que l'histoire canadienne lui accorde une place de choix.

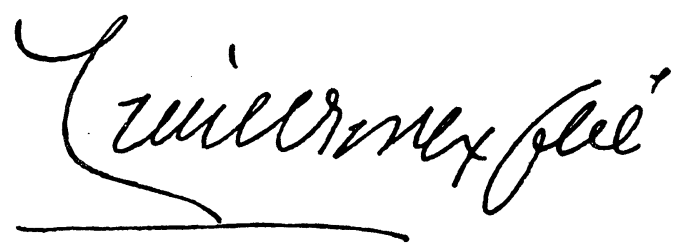

LIONEL GROULX, ptre 


\section{LE VRAI PORTRAIT DE MARGUERITE BOURGEOYS DÉCOUVERT EN 1963}

Ce que nous croyions être le vrai portrait de la bienheureuse Marguerite Bourgeoys a cessé d'exister. Le canevas primitif, débarrassé des retouches et des repeints accumulés depuis plus d'un siècle, révèle maintenant l'authentique portrait peint par Pierre Le Ber, le 12 janvier 1700, immédiatement après la mort de la Bienheureuse.

La restauration fut confiée, en $19 \overline{9} \overline{3}$, à Ed ward O. Korany de New York. A cet artiste-restaurateur de renommée internationale, l'histoire de l'art canadien doit la découverte d'une des toutes premières peintures de notre héritage artistique.

Amateur et primitif, Le Ber ne s'inspire d'aucune école, mais ses limitations techniques sont compensées par une force descriptive peu commune, due à une rare compréhension intuitive du sujet.

Le portrait résume quatre-vingts années d'une vie entièrement vouée à l'exercice de la charité. La perfection et l'exactitude de la synthèse se trouvent attestées dans ce jugement non moins éloquent que bref de l'artiste-restaurateur: COMPASSION.

La toile originale mesure $19^{\prime \prime} \times 24^{\prime \prime}$. 


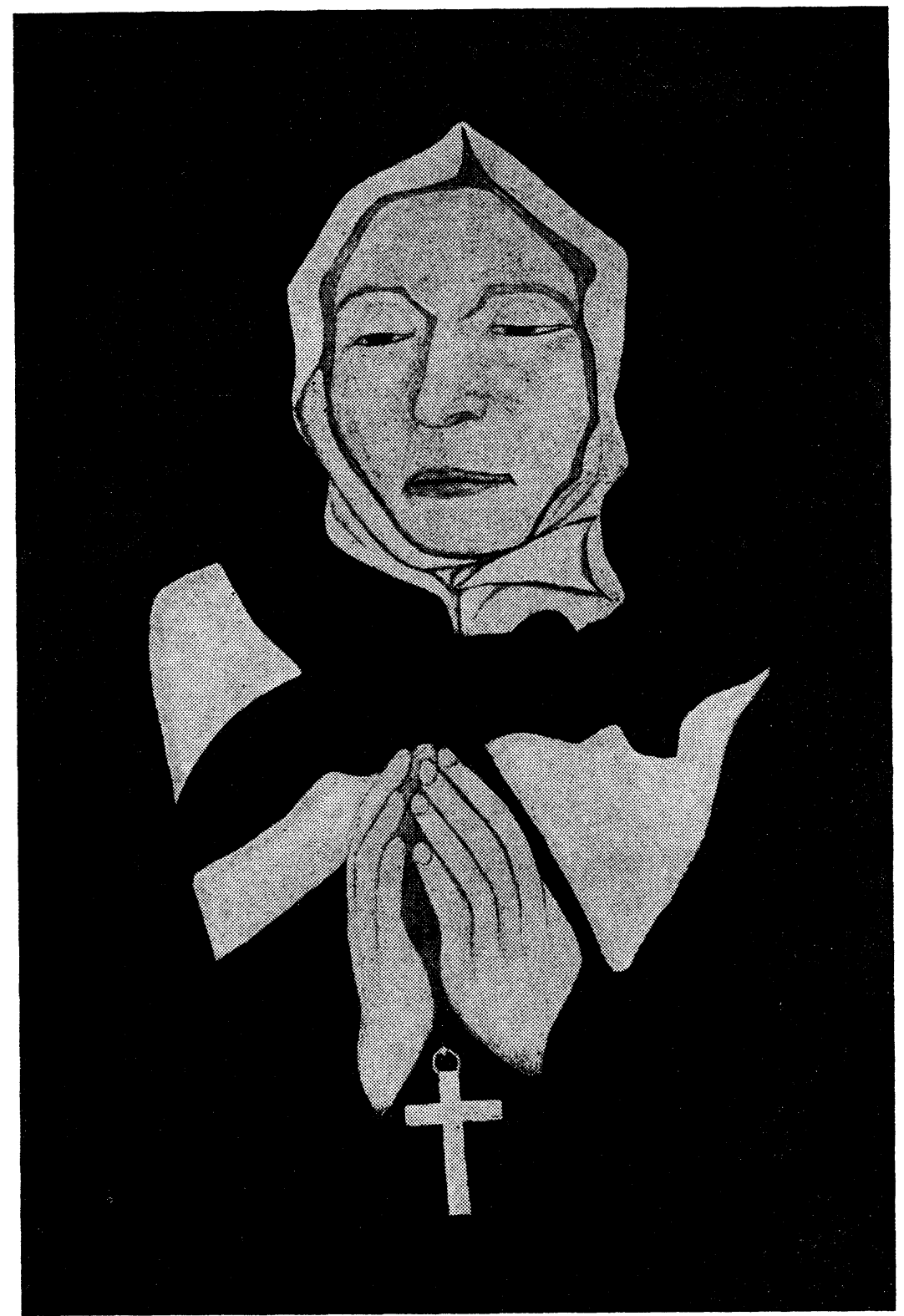

Le vrai portrait

de la bienheureuse Marguerite Bourgeoys
fondatrice de la Congrégation de Notre-Dame de Montréal $1620-1700$ 
$1-1651,26$ octobre

Inventaire, après décès, des biens d'Abraham Bourgeoys.

Archives de l'Aube, 2 E 6/37

Claude Bourgeois, notaire 


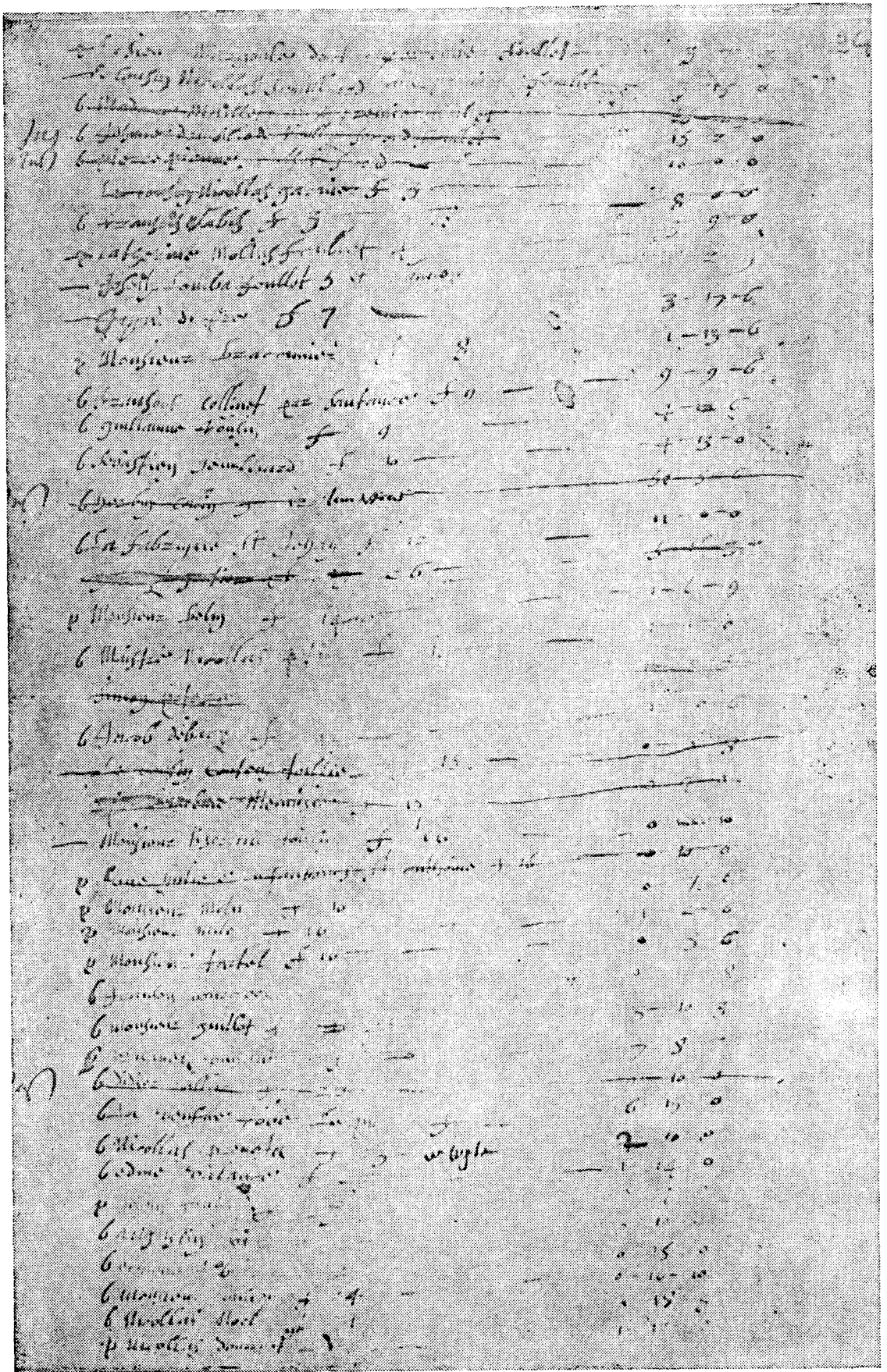


$2-1666,27$ décembre

Reçu donné à M. Le Duct, marguillier de l'église de Ville-Marie pour 80 livres paiement de "blanchiture" et autres besognes de l'église.

Archives du Collège Sainte-Marie, Montréal.

$3-1670,8$ février

Reçu donné à Monsieur de La Brie, marguillier de l'église de Montréal, pour cent livres paiement de blanchissage de linge de l'église.

Archives du Collège Sainte-Marie, Montréal.

$4-1683,15$ décembre

Quittance concernant un terrain de cent livres reçues des Hospitalières pour un terrain de 9 arpents acheté de la Congrégation de Notre-Dame.

Copie photographique - Original perdu. 


$$
\begin{aligned}
& 2-1666 \\
& 3-1670 \\
& 4-1683
\end{aligned}
$$

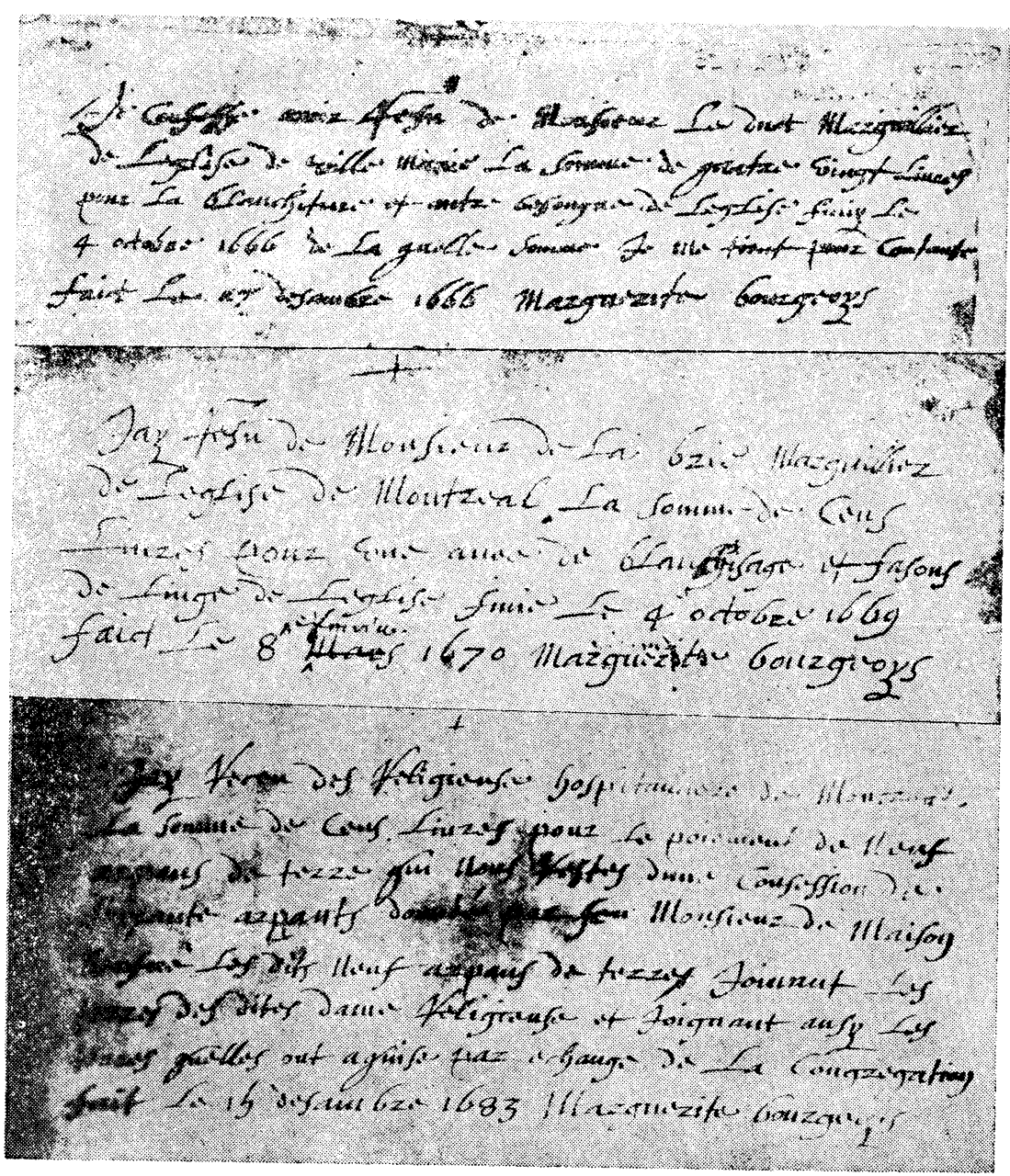


$5-1685,3$ décembre

Mémoire extrait du bail à ferme passé avec Martin Foisy.

Archives judiciaires de Montréal

(Adhémar notaire) 


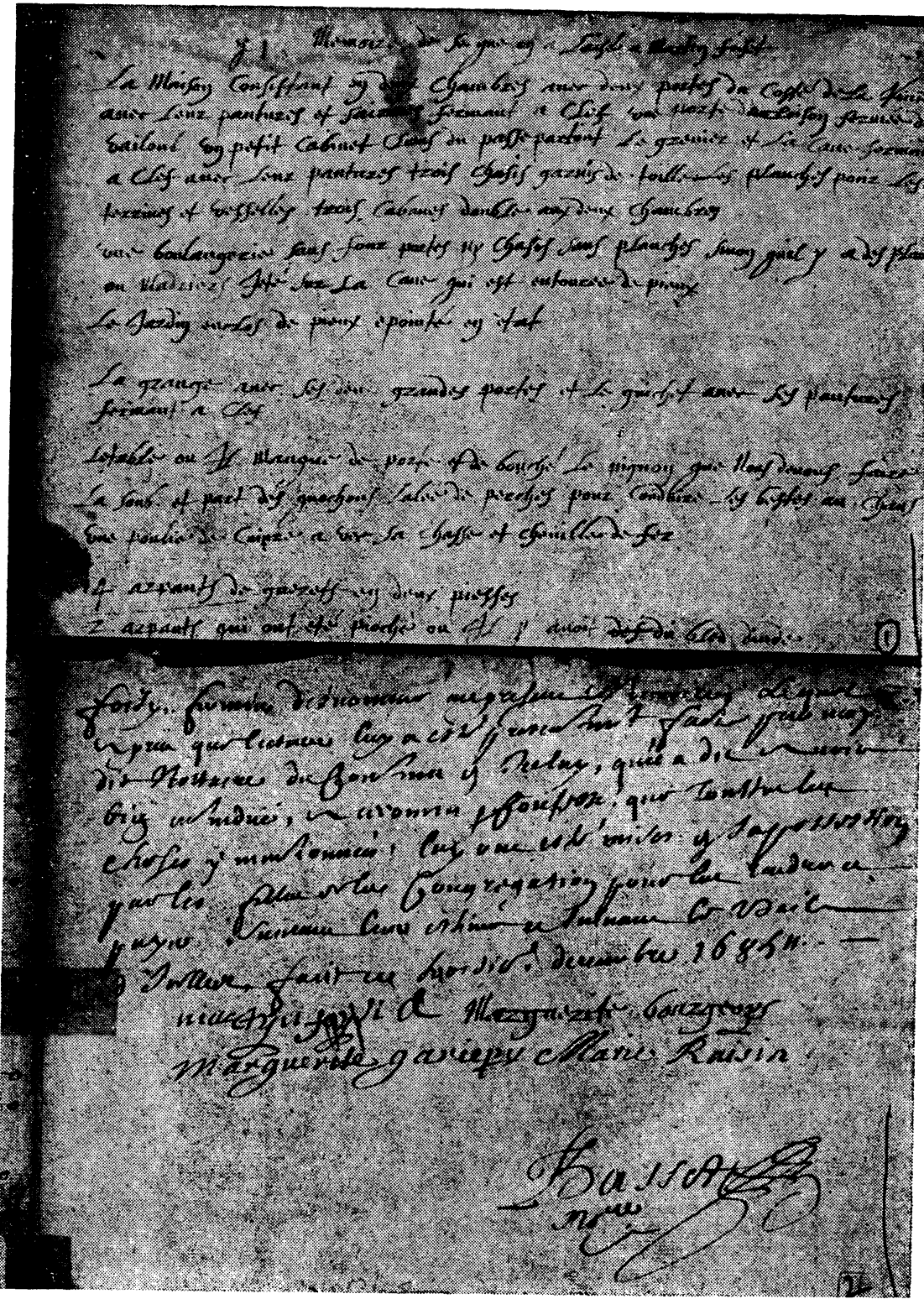


$6-1687$

Copie autographe d'un contrat de l'école Sainte-Famille, Île Saint-Laurent (Île-d'Orléans).

Archives de la Congrégation de Notre-Dame, Montréal 


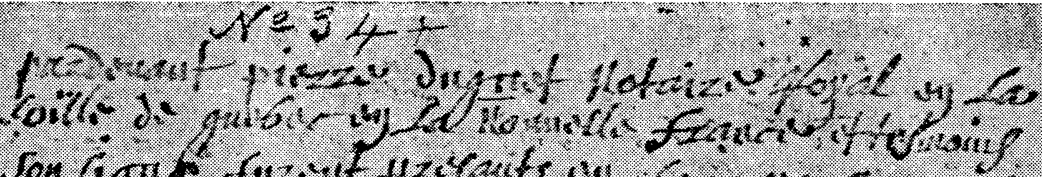

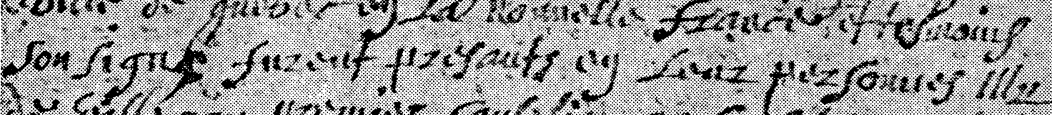

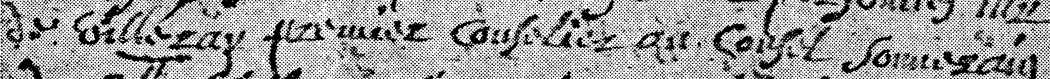

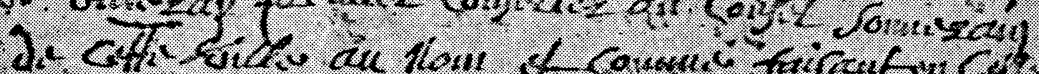

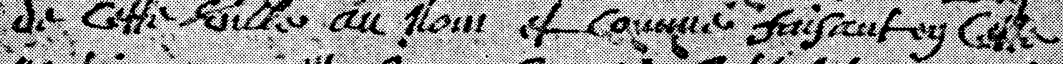

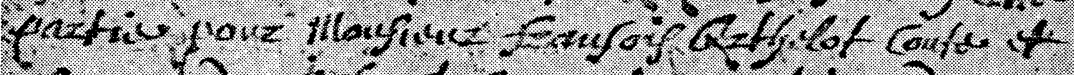

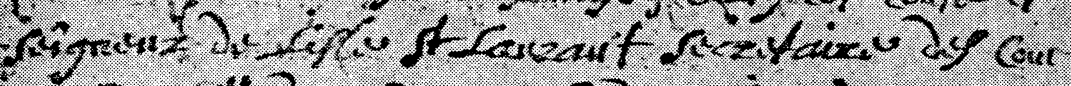

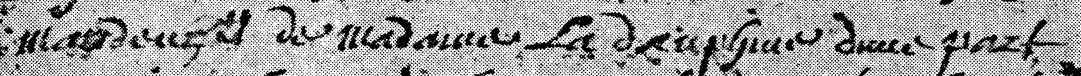

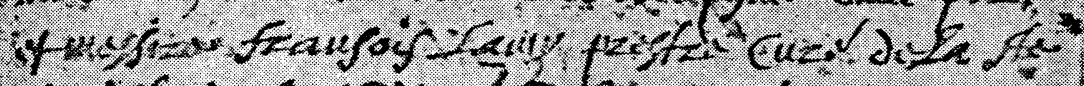

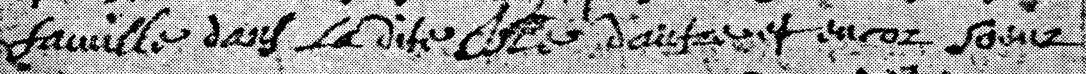

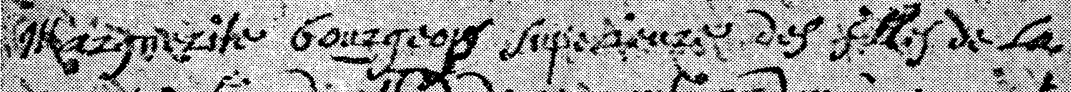

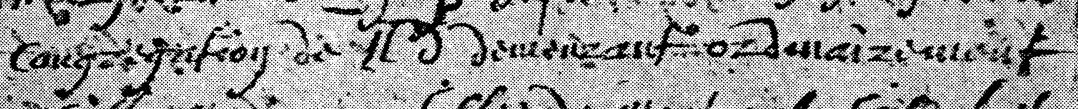

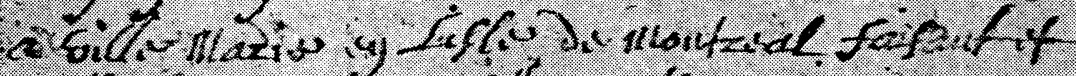

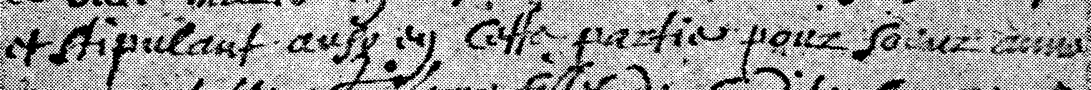

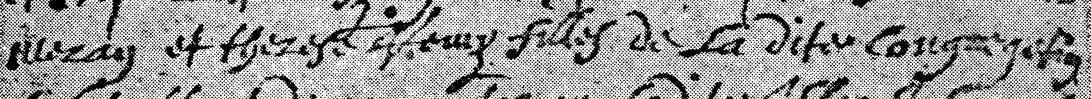

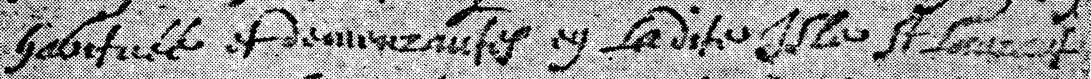

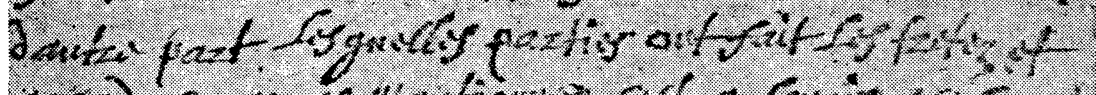

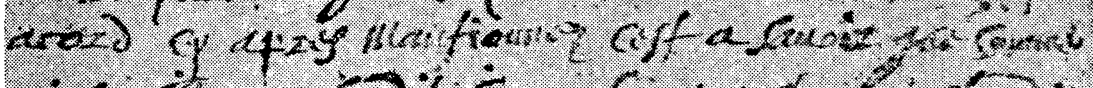

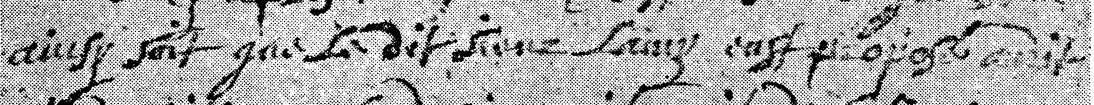

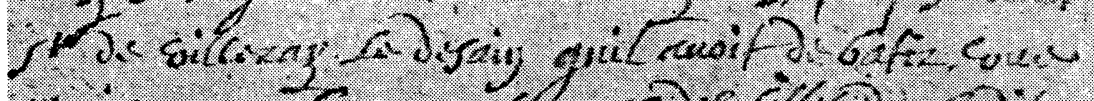

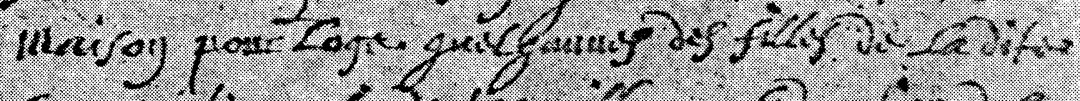

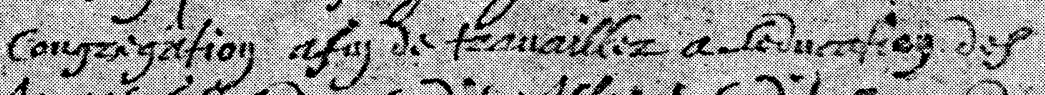

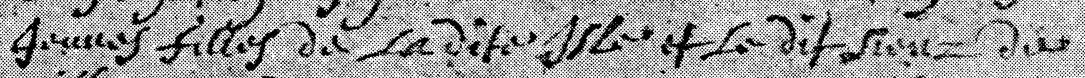

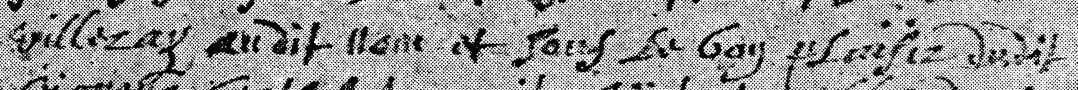

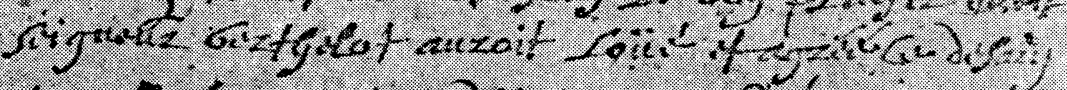

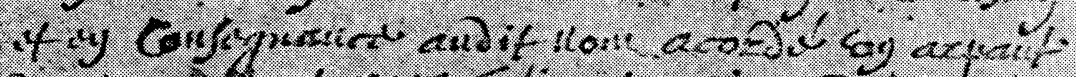

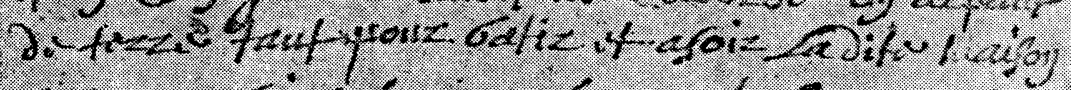

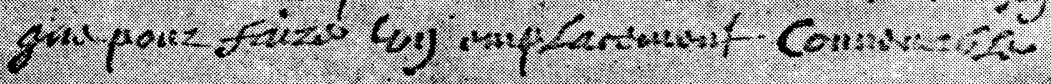


$7-1689,16$ juillet

Copie d'un contrat de concession à André Cire dans le fief du Bon-Pasteur sur l'Île-Jésus.

Archives du Séminaire de Québec Seigneurie 49 


\section{$7-1689$}

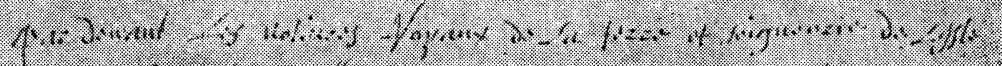

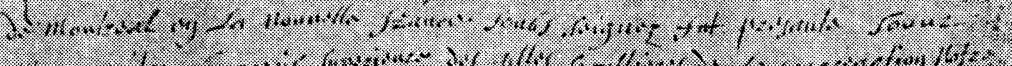

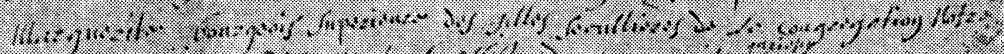

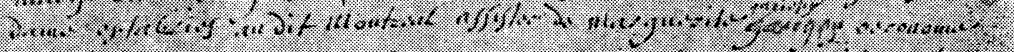

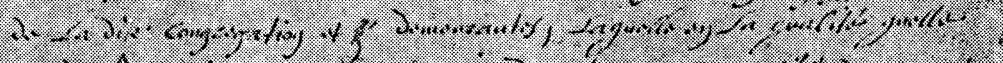

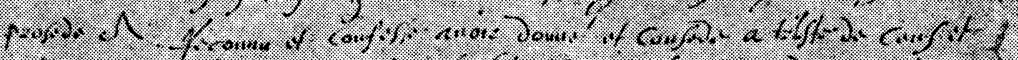

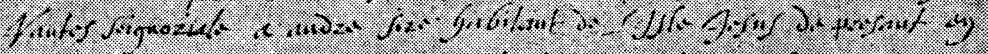

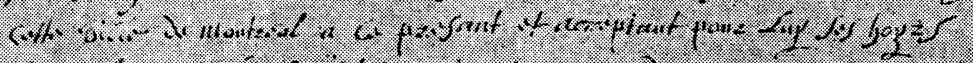

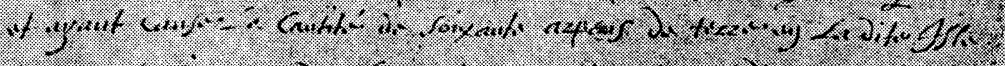

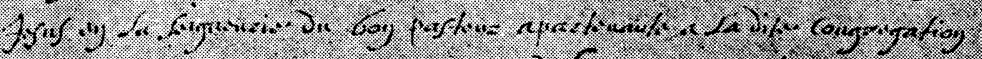

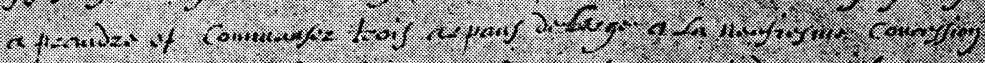

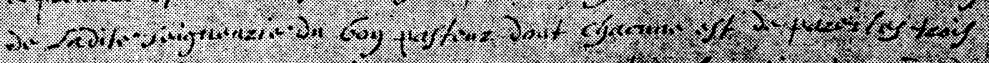

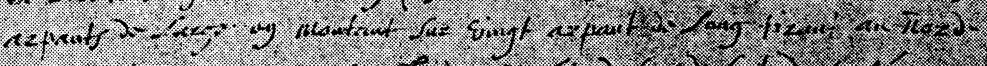

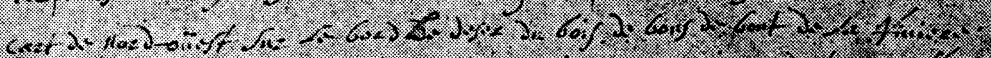

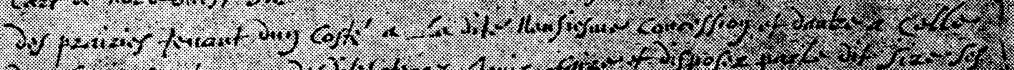

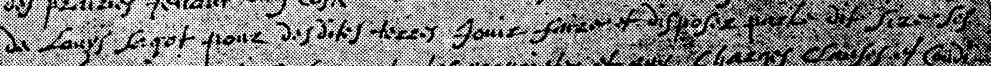

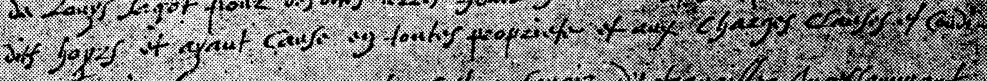

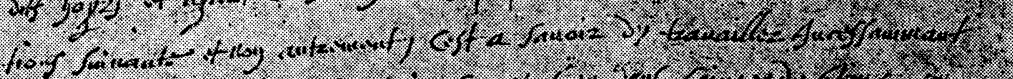

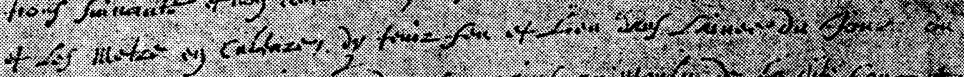

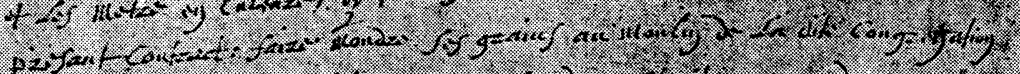

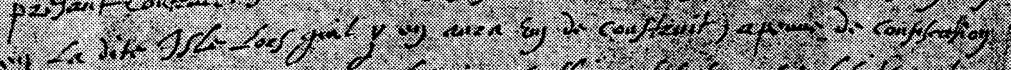

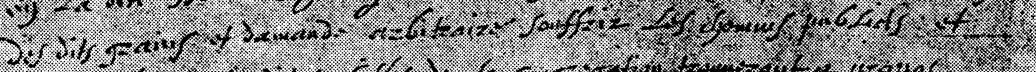
m.

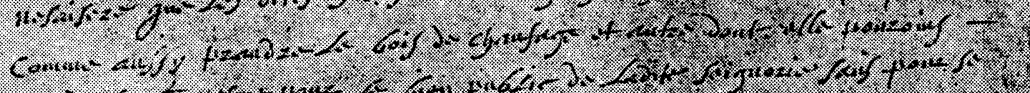

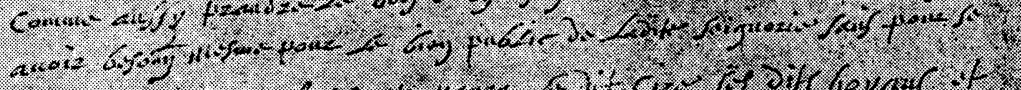

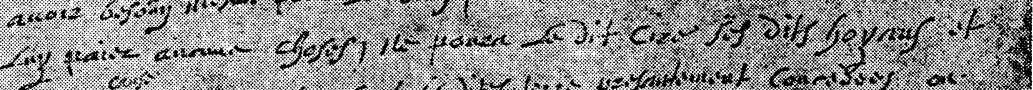

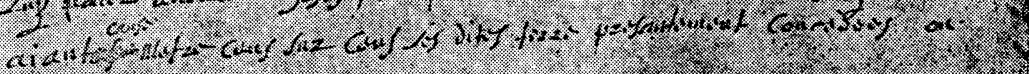




\section{$8-1691,24$ juillet}

Copie d'un procès-verbal concernant une propriété à Pointe-Saint-Charles.

Archives de la Congrégation de Notre-Dame Dépôt général 


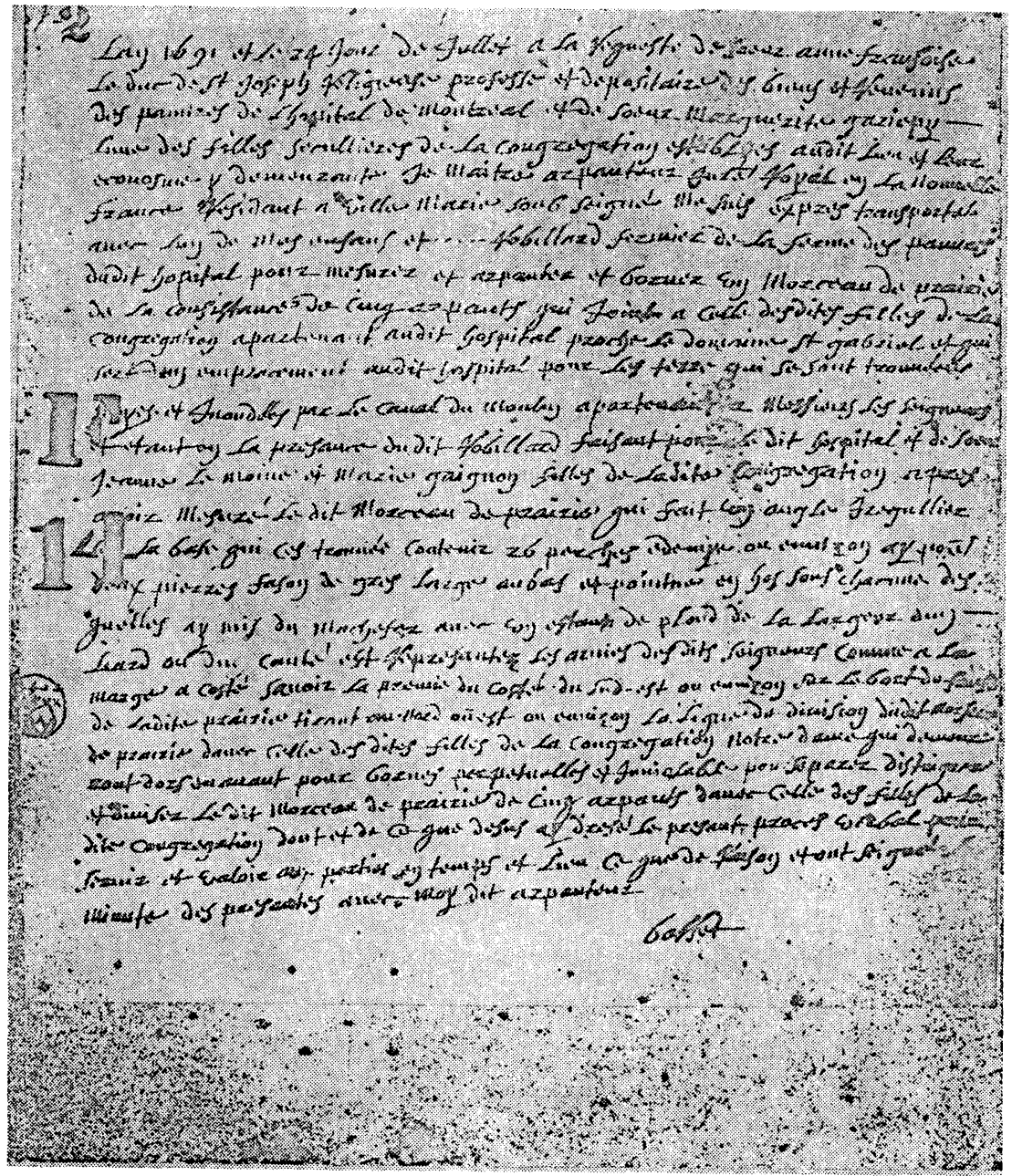




\section{$9-1692,7$ octobre}

Conintrât de veñte, des sueuris de la Congrégation de Notre-Dame à Charles Normand, d'une maison qu'elles possédaient à la Haute-Ville, Québec.

Divers autographes: Notaire Genaple Marguerite Bourgeoys Monseigneur de Saint-Vallier Ursule Gariépy

Monsieur Buisson, ptre, signe aussi le document, mais sur une autre page.

Collection Gagnon

Bibliothèque municipale de Montréal 


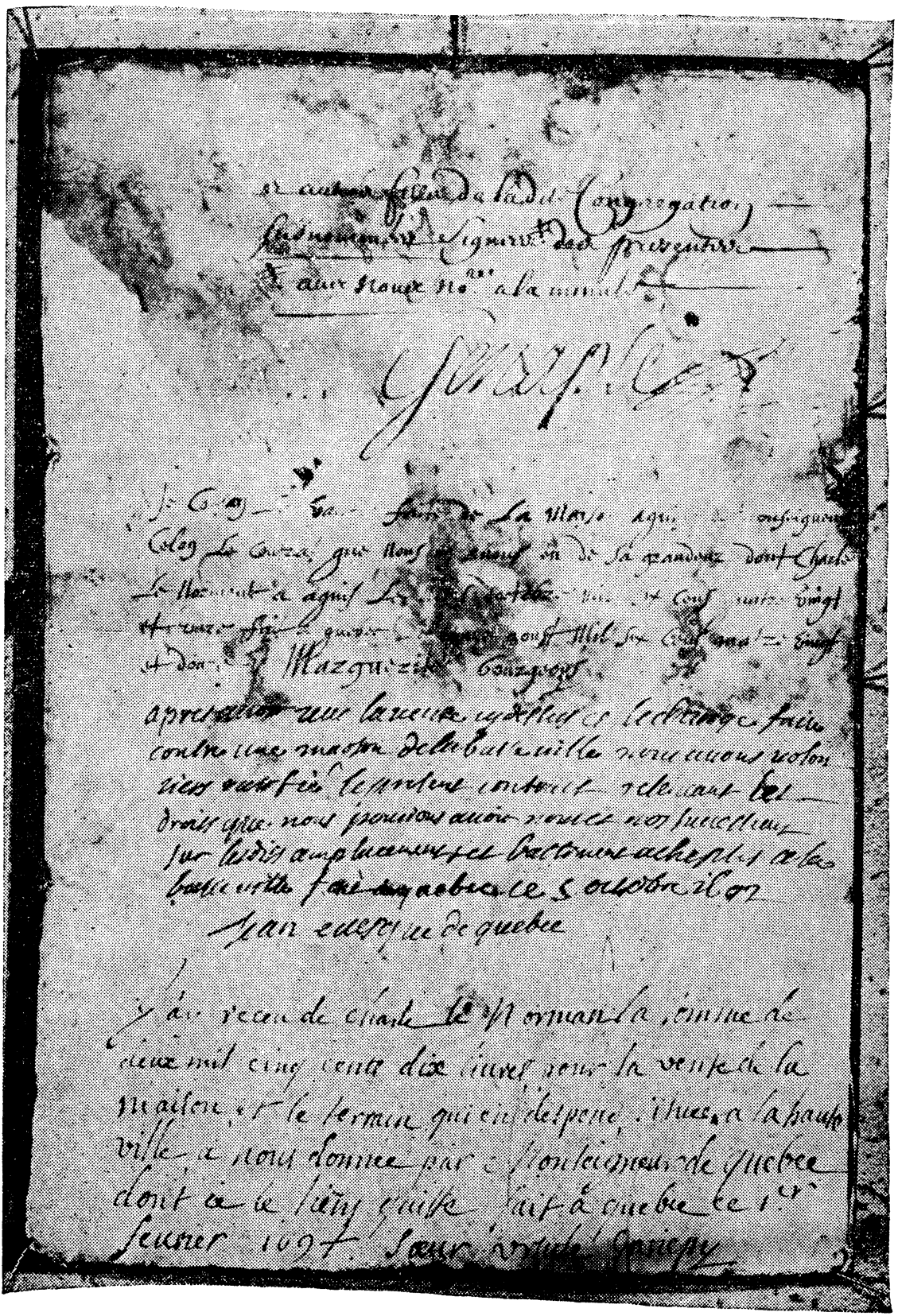


$10-1693,4$ juillet

Prière composée par Mère Bourgeoys

L'original est conservé à la salle du Conseil Général de la Congrégation de Notre-Dame. 


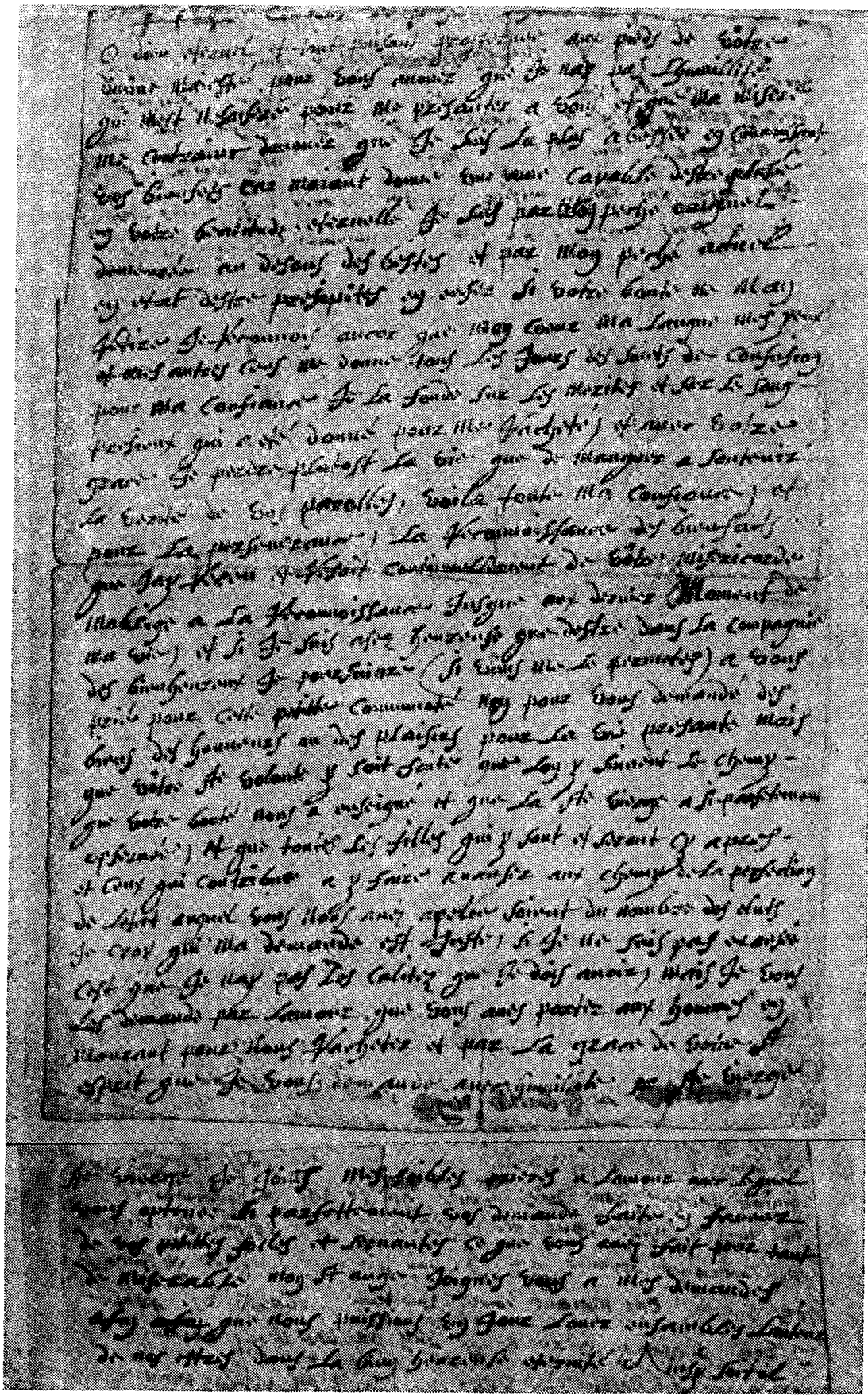


11a) -1695

Suscription de la lettre.

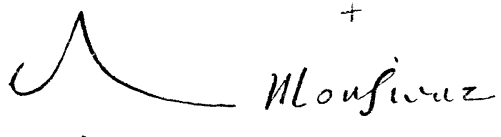

Monfienz troufoy Supezimuz Ju

suniuarze ft sulpirar faulouzg!

st grutaig

Nprazy

11b) - (1695)

Lettre à Monsieur Louis Tronson, supérieur du Séminaire Saint-Sulpice à Paris.

Original perdu Archives de la Congrégation de Notre-Dame, Montréal 
$11 \mathrm{~b}-1695$

Monsi=uz

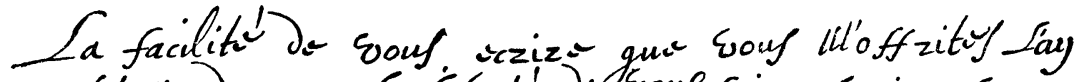

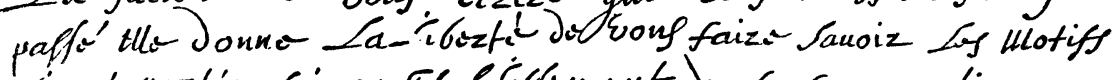
gai ont poztì a faize fitabliffomout da la congzegation a

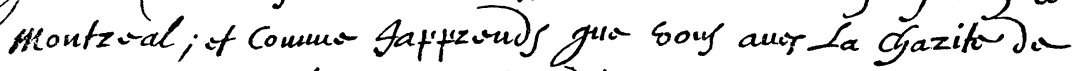
tzanailloz anx fogtonumts gui y doinont Sizuiz, for paffe Suz ma

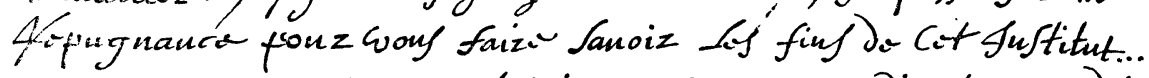

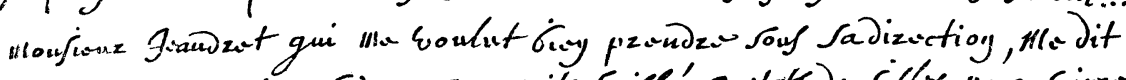

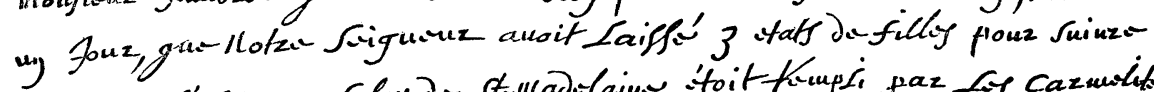

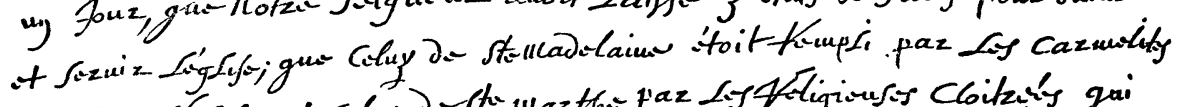

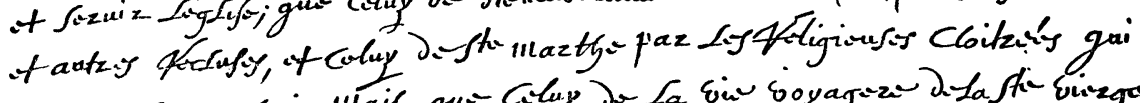

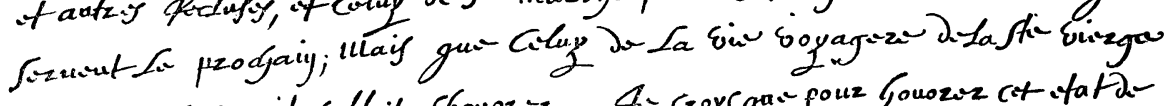

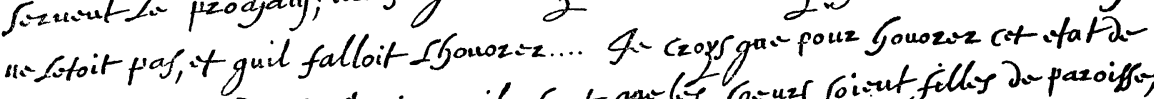

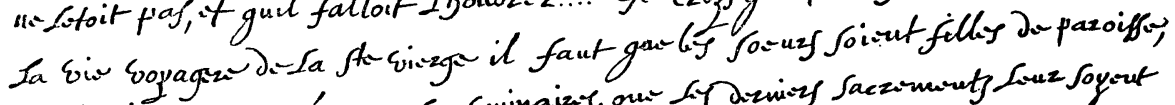

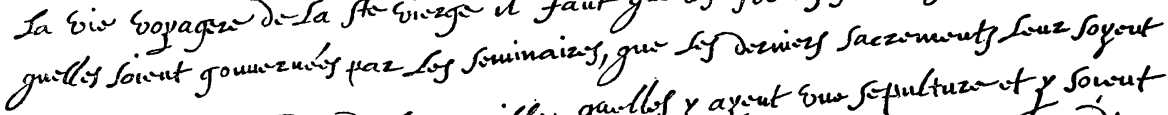

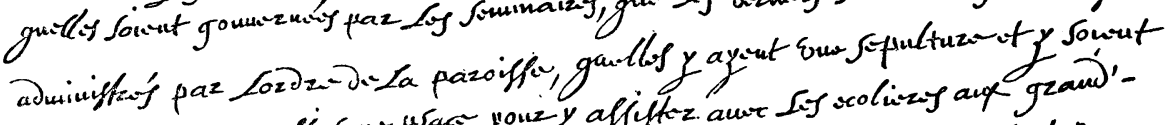

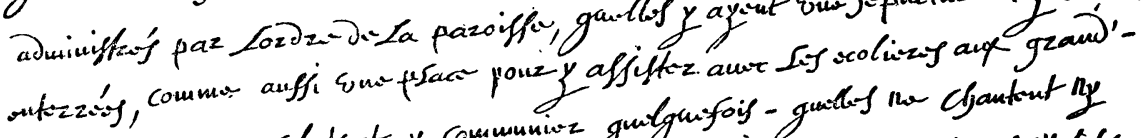

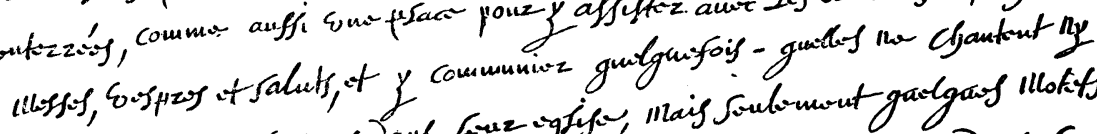

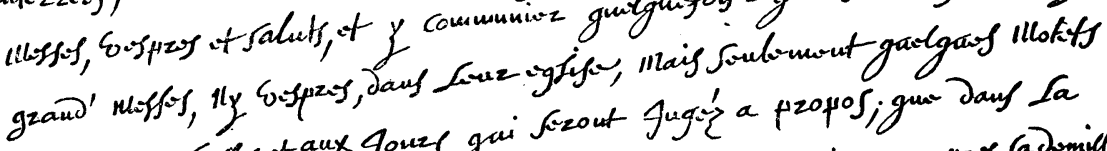

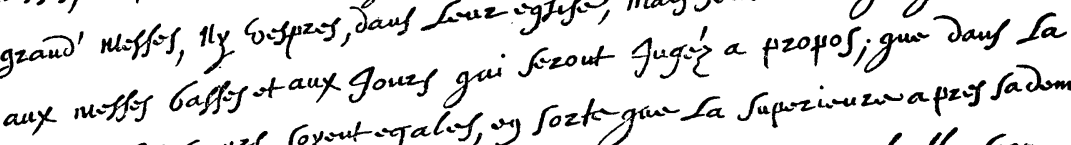

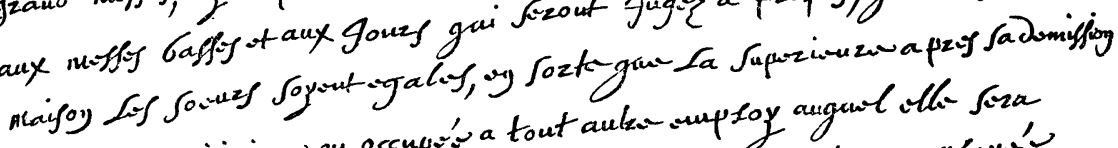

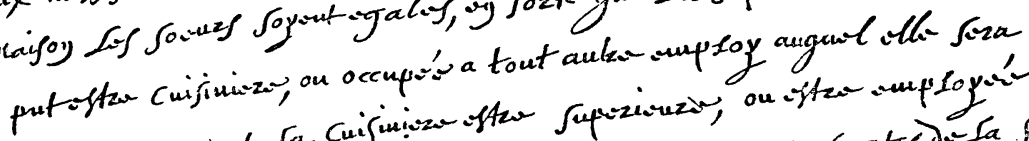

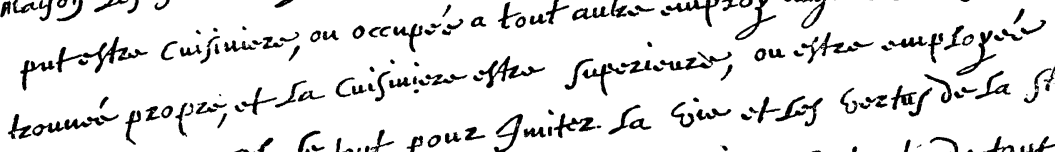

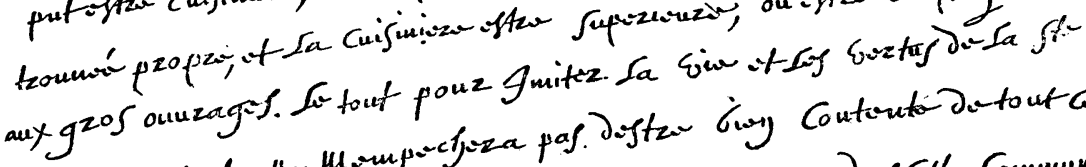

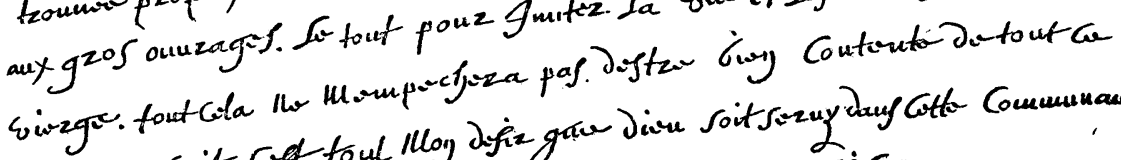

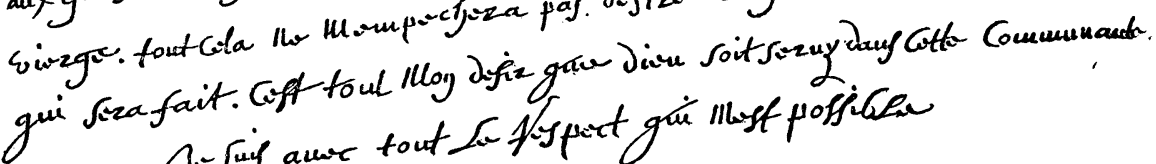

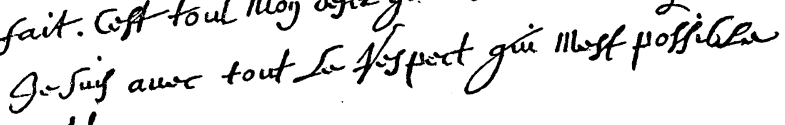
Monfians

coota-f sus obsigen et obvigfantor

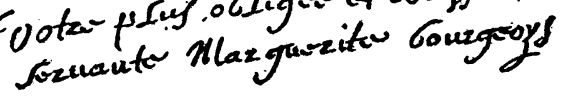


$12-1695,2$ octobre

Lettre à Monseigneur de Saint-Vallier, en France cette année-là.

Les quelques lignes entre la vedette et le corps de la lettre sont de Monseigneur de Saint-Vallier.

Archives de Saint-Sulpice, Paris. 


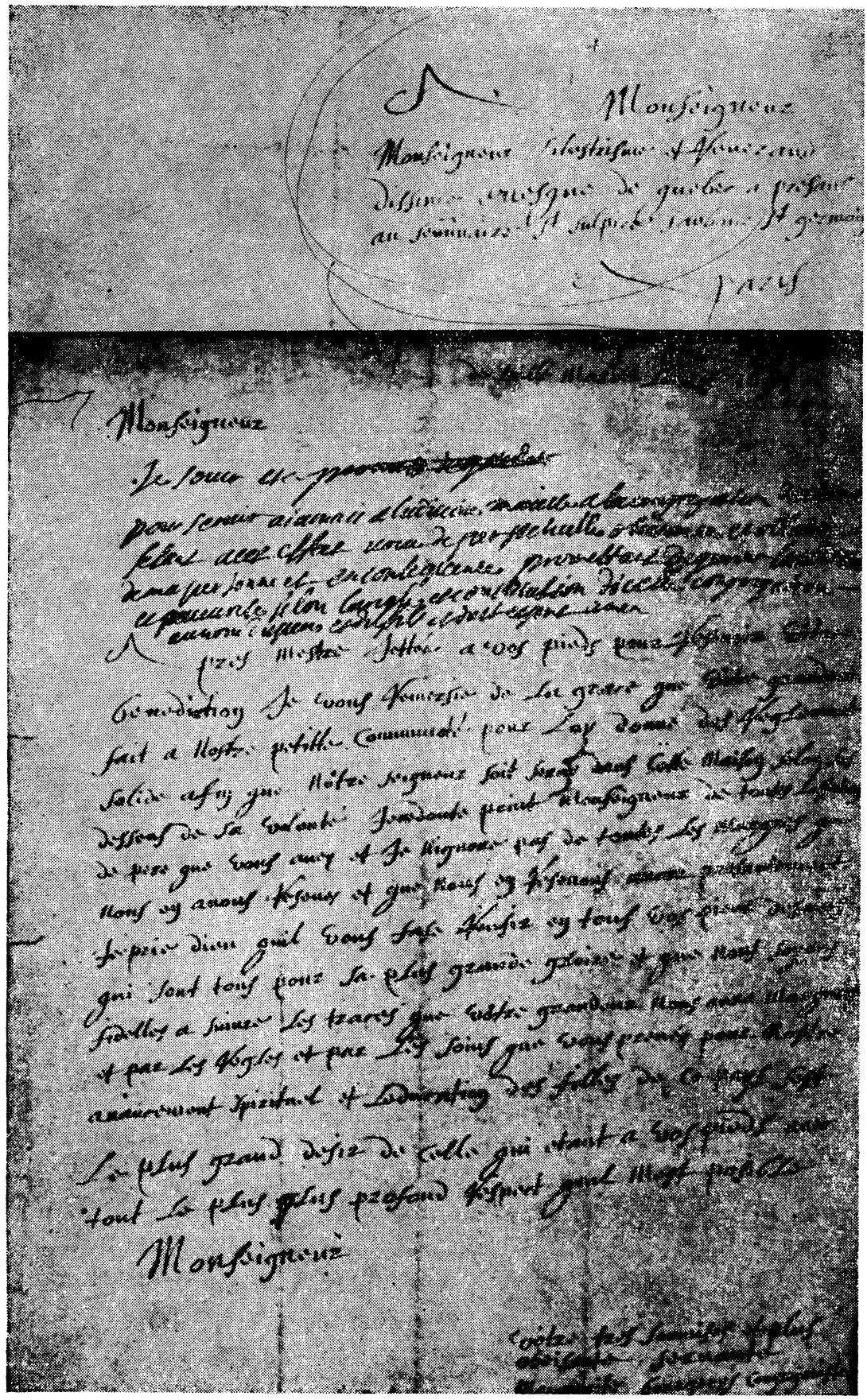




\section{P S}

INTERNATIONAL PSYCHO.SERVICE

[16 nov. 1965]

\section{Ma Révérende Mère,*}

En vous renvoyant cette modeste contribution à votre travail sur votre sainte Fondatrice, je ne saurai assez vous remercier de m'avoir permis de la rencontrer.

Tout cet été, j'ai vécu en sa compagnie dynamique et si maternellement protectrice. Et si j'ai pu écrire ces quelques lignes sur elle, je souhaite que ce soit sous sa direction.

Me permettez-vous d'envoyer une copie à Monsieur Morin de Troyes, qui m'a si aimablement envoyé une photocopie.

Les vôtres vont être soigneusement emballées et vous seront retournées. J'espère que la douane ne les retiendra pas aussi longtemps qu'à l'aller.

J'espère que ce travail correspondra à votre attente et, en vous redisant ma joie de l'avoir mérité, je vous prie de croire, $\mathrm{Ma}$ Mère, à mes sentiments respectueux et dévoués.

\section{A. J. ROQUE}

277, rue St-Honoré - PARIS VIII - OPE. 82-31 - C.C.P. - PARIS 7064-24

* Cette lettre est adressée à Sœur Saint-Damase-de-Rome, c.n.d., directrice du Centre Marguerite-Bourgeoys. 


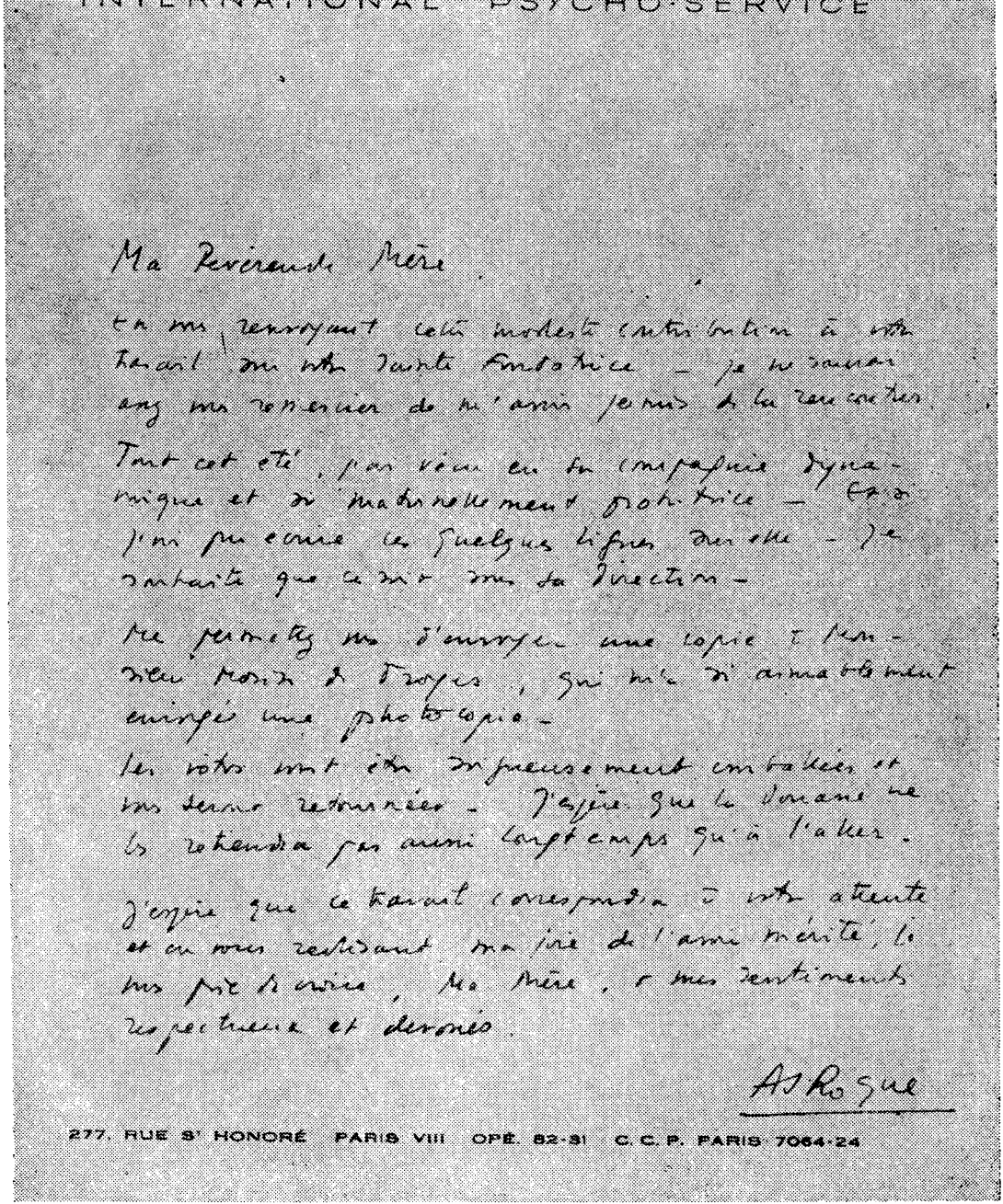




\section{P S}

INTERNATIONAL PSYCHO-SERVICE

Paris

25.11

1965

\section{MARGUERITE BOURGEOYS}

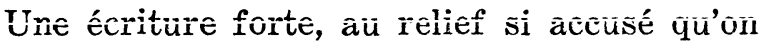
la dirait sculptée; la tension y est à son paroxysme et la sérénité dans sa plénitude, et cela, curieusement, très vite, comme si la vie spirituelle de Marguerite Bourgeoys avait été déterminée et fixée très tôt, sans progression ultérieure.

Le registre de 1651 porte déjà cette marque bien personnelle et de la nature humaine, il ne reste presque plus rien à purifier. Elle est prête; dans les écrits postérieurs c'est un esprit surnaturel qui conduit.

La construction du graphisme évoque le menhir ou la voûte romane. La pression forte et nuancée est d'un équilibre si complet qu'on y retrouve, dans une proportion harmonieuse, les quatre éléments primordiaux.

277, rue St-Honoré - PARIS VIII - OPE. 82-31 - C.C.P. - PARIS 7064-24 
C'est le FEU qui parle le plus haut, mais flamme de cierge qui s'allonge et éclaire, et non pas feu dévorant. C'est lui qui appuie et colore les verticales, qui dresse les hampes vers le ciel.

L'EAU, une eau pure et fraîche, Ma Sœur Eau, vient tout de suite après en complémentarité du feu. C'est la douceur des courbes, la sensibilité discrète des déliés; elle représente l'âme et a considérablement envahi l'écriture en fin de vie.

La TERRE est bien présente, solide, presque massive, encore qu'avisée dans le réalisme et l'énergie de l'action. C'est la pierre angulaire qui a permis au Feu et à l'Eau de s'affronter sans se détruire. On la trouve partout dans le dessin vigoureux et carré, dans ces $\mathrm{R}$ en $\mathrm{Z}$, dans ces angles ou ces cercles si parfaitement précis et fermes.

Enfin l'AIR, qui est Esprit et "souffle où Il veut", a allégé, aéré l'écriture, et lui a donné son dynamisme mystique et, en toutes circonstances, son inspiration juste.

Il y a, dans cette écriture, alliance de l'énergie et de la tendresse à un degré peu commun.

Mais il y a aussi une rare intelligence. L'esprit était large, réaliste et logique. La tournure d'esprit s'apparente aux raisonnements masculins: après une observation précise, concrète, complète des faits, l'opinion est émise ferme, nette, objective, mais définitive. Il n'y a pas une trace de passion dans le jugement, et il n'y a pas à revenir sur ce qui a été dit. Le ton pourrait paraître entier et autoritaire, mais c'est qu'elle était tellement sûre d'être dans le vrai et aussi tellement peu concernée elle-même, d'où cette fermeté détachée. Mais cela n'excluait pas une grande attention aux opinions d'autrui et une ouverture totale dans la discussion.

L'imagination est vivante, fertile, mais toujours utile; pas la moindre trace de rêve, ici, ni de fantaisie. Tout est ordre, mesure, méthode, mais ordre harmonieux, mesure décidée (nous dirions "engagée") et méthode souple. Elle ne devait pas 
manquer de repartie, ni d'une certaine forme d'humour qui s'est estompée avec l'âge, mais qui était émanation drue et savoureuse $\mathrm{du}$ terroir.

Elle voyait loin, elle voyait juste, mais était-ce bien elle qui parlait et agissait ? Tant elle mettait de simplicité à s'effacer, à ne rien dire qui puisse être mal pris ou mal compris. A tous elle parlait le langage de tous, veillant seulement à revenir à la charge, à mieux expliquer, exhorter, prouver, afin de transmettre une idée précise.

Il faut insister sur son amour du détail juste, dans un ensemble bien préparé et cohérent. Rien d'improvisé avec elle, encore que ses initiatives soient opportunes et rapides, mais un excellent sens prévisionnel qui la faisait prudente et économe à bon escient. Et la charité défaisait tout, épuisant énergie et provisions, ce dont elle n'avait cure.

L'absence d'inquiétude est remarquable. Cette femme pratique, avisée, les pieds solidement enfoncés dans les sillons quotidiens, avait des conceptions hardies, neuves, mais non pas aventurières, car on s'apercevait qu'elles collaient immédiatement à la réalité du lendemain et qu'elles étaient indispensables.

C'est cette action qu'il faut étudier de près, car elle s'y est jetée avec intrépidité et un courage indomptable.

Rien ne peut entamer, entraver, désarmer cette écriture de chevalier qui ne ménagera jamais sa personne physique soutenue par une superbe vitalité, qui s'est faite moins nerveuse, moins réagissante au cours des ans, mais ne s'est jamais démentie.

C'est à peine si on peut deviner l'usure dans les écrits les plus tardifs et cependant elle a dû reculer au-delà du possible l'effort quotidien.

Pas de surmenage inconséquent, l'organisation est trop bonne, pas de gaspillage de forces dans cette nature saine et raisonnable, mais la générosité la plus totale qui l'a toujours 
fait s'oublier totalement. Ses satisfactions légitimes, repas, confort ne comptent plus; elle a très vite et absolument maté son corps.

Cette volonté sans failles, sans hésitations ni faiblesses l'a soutenue, mais a surtout bien servi son entourage qui devait spontanément s'appuyer sur elle et en attendre tout.

Elle a le geste de la femme forte qui porte, et porte encore ses enfants, sans qu'il y ait la moindre nuance possessive et abusive, mais seulement l'aide inconditionnelle, constante, spontanée, alors même qu'elle s'est effacée et cachée dans le groupe.

Elle reste celle qui tient.

Et le graphologue peut affirmer qu'elle tenait bien, dans tous les sens du mot. Elle tenait debout, face à l'adversité, seule, droite, sûre d'elle parce que mue par l'Esprit. (Cette vaillance n'a rien d'humain, c'est celle de l'âme missionnée).

Elle tenait d'une main ferme (la Règle étrette) car elle était consciente de ses responsabilités, elle ne voulait rien perdre, rien détourner de ce qui lui était confié. On pouvait la trouver exigeante et intransigeante, mais ce n'est qu'une forme d'Absolu chez elle car, au contraire de ses dires, on ne peut, en rien, trouver son écriture "étrette". Le mouvement est souple, abandonné à l'inspiration et aux accidents du terrain, il permet une adaptation raisonnée, gaie aussi. Aucune sévérité ici. Irrésistiblement attirée par ce qui est grand et beau, elle veut y attirer les autres, mais ce sera par l'amour et non par la crainte.

Un amour chaud, manifesté sans gêne mais avec retenue, et comme en dehors d'elle-même. Elle aimait sur terre par procuration. Elle n'était que la main qui rassure, que les lèvres qui sourient ou appellent, et devait intérieurement se faire reproche d'être si piètre exécutante, car son oubli de soi était réel.

Elle s'est attachée très fort, très fidèlement, très maternellement, mais comme en dénouant à mesure les liens sensibles, 
pour garder les mains ouvertes et tendues à tous les nouveaux venus.

C'était une passionnée. La vigueur du trait l'affirme, et une sensibilité aiguë surgit dans les moments de grande émotion ou d'inspiration. A ce titre, la prière de 1693 est éloquente, nulle part ailleurs on ne retrouve cette vibrance, ni ce rayonnement affectif. Mais elle a su se cacher derrière un comportement discret et uni.

Son geste était rapide et calme, toujours parfaitement sobre et efficace. L'essentiel est vu, dit, exécuté, mais la part et la liberté de chacun sont intégralement respectées. Une conviction et un zèle contagieux, mais ni autoritarisme ni pression: elle sait que toutes les routes convergent dans l'Infini et que chacun a son propre sentier à découvrir et à suivre. Le sien lui a été donné ou imposé avec une évidence et une intransigcance presque implacable, mais elle y obéit dans l'heure et c'est vertigineux de voir cet abandon coexistant avec cette volonté d'action si fougueuse. Elle a pu dire pleinement: "Ce n'est pas moi qui agis..." Et cela sans retour sur soi, ni reprise, ni retard.

Avec cette intensité d'émotion et d'énergie, on peut supposer qu'il y a eu des combats intérieurs, et qu'ils furent rudes. Mais c'est un autre aspect de cette femme étonnante: d'être tout à la fois limpide et secrète, absolument franche, loyale, directe, ne mâchant pas ses mots à l'occasion, ne celant pas ses intentions, ouverte à tous, en confiance et en amour. Et en même temps, taisant avec une extrême rigueur ce qui n'est pas indispensable de faire connaître. De ce qui se passe intérieurement, rien ne transperce ni ne peut se déduire. Son attitude restera égale, vigilante, active; ses propos opportuns et équilibrés.

Rien ne vient trahir la peine, le poids, le doute qui la torturent. Et pourtant le dernier texte soumis (1695) a un écrasement, des brisures qui parlent. Marguerite Bourgeoys souffre. Une souffrance riche, féconde, qui constitue pour sa générosité un trésor inépuisable. Elle avait choisi l'infini de Dieu, elle se heurte aux limites d'une Maison ou d'un corps 
affaibli, et elle souffre... Et c'est alors que les traits de son visage, si fortement accentués, rejoignent son geste graphique, évocateur de cette personnalité authentique.

Elle n'est plus qu'une belle âme, ou belle flamme, toute donnée à Dieu, à sa Congrégation qui est vraiment sa chair et son sang, et à tous les autres, mais seule, indiciblement seule.

A. J. ROQUE

16 nov. 65 